\title{
O que a pós-graduação pode esperar dos tecnólogos em Design de Interiores: relato de experiência na disciplina Projeto Interdisciplinar
}

\author{
Thábata Regina de Souza Brito; \\ Sâmela Suélen Martins Viana Pessôa
}

resumo:

O presente artigo compreende o relato de experiência teórico-prática de ensino trabalhada na disciplina Projeto Interdisciplinar de um curso tecnólogo em design de interiores, realizada em três campus da região metropolitana de Belo Horizonte - MG. A pesquisa evidenciou situações reais, presentes no cenário complexo que envolvem a atuação em design e promove a formação continuada para alunos tecnólogos na pós-graduação. Para isso, será apresentado o percurso teórico que fundamentou as construções teórico-reflexivas, tais como: o ensino superior em design de interiores; os processos didáticos adotados na disciplina; o protagonismo do discente; método e ferramentas do design que exploram a geração de solução que tocam dimensões estratégicas em design. Como parte do desenho metodológico, o artigo se caracteriza pela pesquisa do tipo qualitativa com estudo exploratório para fundamentar teorias e o relato de experiência que possibilitou evidenciar as práticas de ensino e resultados obtidos com a experimentação projetual.

\section{palavras-chave:}

Formação Tecnóloga; Design de Interiores; Design Estratégico; Relato de Experiência 


\section{Introdução}

A produção de vivências extensionistas no contexto do ensino e formação superior tem apresentado a necessidade da adoção de práticas que promovam a autonomia e o protagonismo discente. Este fato nos permite pensar uma formação comprometida com os reais desafios sociais e oportunidades para a continuação do ensino superior e a inserção de novos designers no mercado de trabalho. Nesse sentido, o artigo busca indagar quais as expectativas da pós-graduação sobre os discentes com formação superior tecnológica em design.

Para construir um pensamento teórico-reflexivo a pesquisa estabelece como objetivo central apresentar um relato de experiência sobre práticas pedagógicas de ensino adotadas por uma disciplina do curso tecnólogo de design de interiores e sua relação com a formação continuada.

Para isso, inicialmente, será apresentada a contextualização do ensino tecnólogo em design de interiores. Na sequência, irá apresentar o desenho de uma disciplina dentro do curso tecnólogo que considera o diálogo entre a teoria e prática a partir de um olhar estratégico em design para responder diferentes problemas sociais reais. Para evidenciar os resultados alcançados com as práticas adotadas, será apresentado um relato de experiência sobre a vivência na disciplina com os estudos realizados.

Como desenho metodológico o presente artigo caracteriza-se pela pesquisa qualitativa pois estabelece como ponto de vista social questões eminentes de grupos de pessoas, nos quais a investigação será orientada à compreender as atitudes, preferências, opiniões e sondagens contextuais. Trata-se de uma pesquisa exploratória que utiliza da técnica relato de experiência para evidenciar o processo de experimentação projetual que orientou a proposição em design. $\mathrm{O}$ estudo se orientou a relatar e analisar as práticas pedagógicas aplicadas aos processos de ensino e aprendizagem. Configura-se como um registro descritivo das docentes, bem como de suas percepções sobre os resultados obtidos durante o processo de orientação e desenvolvimento do desafio projetual em design.

\section{Desenvolvimento}

\subsection{0 ensino superior em design de interiores e seu legado para a pós-graduação}

A qualificação em nível superior é determinante para o bom posicionamento profissional dos indivíduos na sociedade. De forma que, o sujeito procure manter o aprendizado e complementação da sua formação inicial, seja ela de nível médio ou superior. A escolha do design, e de todos os outros cursos superiores, seja na graduação ou na pós-graduação, é essa preocupação do indivíduo na busca pela capacitação pessoal e profissional. Podemos tratar do ensino na pós-graduação, mas precisamos analisar e entender como estão sendo ofertados os cursos de graduação em Design, em especial, do Design de Interiores no contexto brasileiro.

Há quatro anos, em 2016, existiam 742 cursos de Design registrados no portal do Ministério da Educação - MEC. Divididos entre os graus de formação de bacharelado e tecnólogos. Nesse mesmo período, verificou-se 38 diferentes nomenclaturas para designar a atividade ao campo do design, dentre esses 742 cursos (SCHNAIDER; FREITAS, 2016). Nessas 38 terminologias estão incorporadas o próprio design, design gráfico; design de produto; design de moda; design de interiores; design digital; design educacional; design de games; design de animação; entre outros. Todos eles abarcam essa grande área de atuação que é o design.

Para o desenvolvimento dessa pesquisa foi consultado o portal do MEC como consulta para averiguar os dados dos cursos superiores em Design e Design de Interiores no ano de 2020. O portal do Ministério da Educação permite a pesquisa em quatro links específicos: Consulta interativa; consulta textual; consulta avançada e IES extintas. Nessa pesquisa foram utilizadas a consulta interativa e a consulta textual. Na página da consulta interativa tem todas as instituições de educação superior e todos os cursos cadastrados no MEC distribuída por estados, no qual após a seleção do estado e a escolha do curso apresenta todas as instituições de ensino superior que oferecem aquele curso, como também o nível de graduação, a data de início do curso e a modalidade, presencial ou a distância. O acesso a consulta textual disponibiliza as opções para consultar as instituições, cursos de graduação, curso de especialização e endereço ou também chamado local de oferta (SCHNAIDER; FREITAS, 2016). 
Na pesquisa desenvolvida no site do e-mec (MINISTÉRIO DA EDUCAÇÃO, 2020) na consulta interativa foram identificados 2 cursos superiores em Design de Ambientes, um em Decoração e um em Decoração e Design e 484 cursos superiores em Design de Interiores e na consulta textual o número passou para 400 cursos $^{1}$. Em ambas ferramentas, de todos os cursos superiores existentes no campo do design o curso de Design gráfico é o que possui maior disponibilidade seguido pelo curso o Design de Interiores. A exemplo, na ferramenta da consulta textual existem 417 cursos de Design Gráfico no país comparado aos 400 de Design de Interiores.

Dos 484 cursos superiores em design de interiores, apenas 10 possuem o grau de bacharelado e 474 são tecnólogos. Os dois cursos superiores em Design de Ambientes são para a formação de Bacharéis como também, o curso de Decoração e Design. O curso de Decoração oferecido pelo Centro Universitário Teresa D'ávila - FATEA é o único que proporciona a formação em licenciatura na área no contexto brasileiro.

Os cursos de bacharelados em Design no Brasil possuem características específicas diferentes dos cursos superiores tecnológicos. No Bacharelado a carga horária mínima consiste em 2.400 horas com uma duração de 3 anos (mínimo) na modalidade presencial. A modalidade tecnólogo possui a natureza de graduação, com seu formato mais compacto, sua duração é fixada entre 1.600 horas a 2.400 horas com duração mínima de dois anos, com caráter técnico e menos teórico devido a redução do tempo (SCHNAIDER; FREITAS, 2016).

O diploma de graduação dos cursos tecnólogos em design tem a mesma validade que dos cursos de bacharelados para a participação em concursos públicos de níveis superior e em cursos de especialização e de pós-graduação. A área de regulação da educação profissional do Ministério da Educação valida ambos documentos como graduados na área (MINISTÉRIO DA EDUCAÇÃO, 2020).

Em caráter explicativo, existem cursos sequenciais em design de interiores e decoração. Os cursos sequenciais são considerados cursos superiores, mas não de graduação. Eles são divididos em sequencial de formação específica, nos quais o aluno recebe um diploma ao final do curso e o sequencial de complementação de estudos que confere o certificado para o educando ao final do curso (SCHNAIDER; FREITAS, 2016). Nessa pesquisa, não estamos tratando desses cursos de design, mas identificamos a existência dessa modalidade, que é minoria, no ensino brasileiro.

Em contradição ao ensino superior brasileiro que apresenta 16\% das ofertas de graduação para os cursos superiores de tecnologia (MINISTÉRIO DA EDUCAÇÃO, 2020), o campo do design de interiores possui $97 \%$ da sua graduação nos cursos tecnólogos, sendo apenas 14 instituições ofertando os cursos de bacharelados. Esses dados são uma resposta a necessidade do mercado atual. A escolha do aluno pela modalidade tecnóloga é devido a maior rapidez de ingresso ao mercado de trabalho e início da vida profissional. A maior concentração de cursos superiores tecnológicos está na região sudeste do país (SCHNAIDER; FREITAS, 2016).

No curso tecnólogo há o direcionamento dos conteúdos voltados para os aportes técnicos da profissão em design de interiores, no intuito de interligar a academia e o mercado de trabalho às necessidades das relações humanas e de bem-estar, assim como ao uso de novas tecnologias e aos parâmetros de sustentabilidade ambiental, econômica e social. Todos os elementos técnicos são fundamentados com teoria nessa modalidade de ensino, mas em nenhum grau de aprofundamento. A proposta dos cursos tecnólogos em design de interiores é fornecer ao mercado bons profissionais, com a liberdade para o discente prosseguir com o seu processo de aprendizagem. De forma que, os alunos dos cursos tecnólogos também, podem e devem dar continuidade aos seus estudos e por isso a pósgraduação é uma possibilidade de continuidade na sua formação superior.

\footnotetext{
${ }^{1}$ A diferença de números apresentados na consulta interativa em relação a consulta textual é devida a seleção das informações em cada página. Nos dados da consulta interativa aparecem cursos que foram cadastrados no MEC mas ainda não iniciaram efetivamente as atividades e cursos que estão em processos de encerramento com as últimas turmas funcionando. Nessa pesquisa utilizaremos os dados fornecidos pela consulta interativa.
} 


\subsection{Processos didáticos adotados na disciplina de um curso tecnólogo em design de interiores e fundamentação do design para o relato de experiência}

Dentre as instituições que ofertam o curso de design de interiores no estado de Minas Gerais, considerou-se para análise e estudo algumas práticas de ensino adotadas em um Centro Universitário multicampi, com sedes estabelecidas nas cidades de Belo Horizonte, Contagem e Betim. Como parte da grade curricular do curso tecnólogo de Design de Interiores, oferecido por essa instituição, se encontrava a disciplina: Projeto Interdisciplinar. Esta era responsável por criar um diálogo interdisciplinar com as demais disciplinas que compunham a formação do aluno e permitiam a prática mediante uma vivência projetual.

Nesse sentido, a disciplina admitiu uma abordagem exploratória no pensamento estratégico em design e a expansão das possibilidades e caminhos de solução. Por tais características, identificouse como oportunidade de experimentação a proposição de uma ação de design que relacionasse conhecimentos teóricos e práticos a partir de um olhar estratégico em design para responder problemas sociais reais.

Como parte da abordagem pedagógica adotada buscou-se pela metodologia ativa e seu foco no protagonismo discente que considera o processo de produção do conhecimento uma resultante da inserção do aluno em processos de participação ativa que compreende a identificação de problemas desafiadores e a proposição de respostas.

Sobre a aplicação de metodologias ativas de ensino em disciplinas de formação superior, Celestino et al (2020) vai afirmar que esta consiste em um modelo de ensino construtivista que considera o aluno como protagonista e responsável pelo próprio aprendizado, além de colaborar para uma formação que estimula a autonomia na atuação profissional. Assim, a metodologia ativa vem sendo aplicada em diferentes contextos de ensino público e privado e se configura como um modelo orientado a resolução de problemas sociais, os quais os alunos a partir de uma abordagem individual ou coletiva se dedicam a explorar questões e buscar soluções estratégicas. Esse modelo permite a construção do pensamento crítico, reflexivo e exploratório. O professor atua como um facilitador das experiências de aprendizagem numa abordagem dialógica orientada a construção do conhecimento, a reflexão e a tomada de decisões.

Um dos procedimentos adotados ao longo do processo de elaboração de uma solução em design foi a orientação a partir de marcos pré-estabelecidos de desenvolvimento, que permitiu o acompanhamento e o avanço na exploração do problema, bem como a identificação de oportunidades para mitigá-lo. O modelo adotado, associado a um ambiente pedagógico propício, colaborou para a participação ativa e autônoma do aluno no processo de produção de experiências mais profundas de aprendizagem.

Segundo Fernandes (2016), um dos elementos definidores de novas experiências de aprendizagem consiste na construção de um ambiente pedagógico que seja capaz de oferecer aulas indutoras da participação ativa de alunos. Nesse sentido, é possível adotar práticas que promovam a inovação no ensino transcendendo aos limites presentes em contextos desfavoráveis em seus aspectos político-sociais e organizacionais.

Para desenvolver o pensamento estratégico e a visão sistêmica em sala de aula alguns autores como Rafael Cardoso, Zygmaunt Bauman, Dijon de Moraes, Peter Jones entre outros, foram referenciados na disciplina.

Durante o semestre foi desenvolvido com os alunos conceitos das temáticas do design thinking, design de serviços e gestão do design, a fim de possibilitar e desenvolver no discente uma visão mais ampla do campo do design. Tal fundamentação objetivou amparar o discente no processo de identificação e resolução dos problemas reais na esfera macro da sociedade e não, somente, em problemas pontuais concernentes aos projetos em design de interiores. Dessa maneira, os alunos foram incentivados a reconhecerem novos campos de atuação no design, como também, mapear nichos de mercado em detrimento das oportunidades identificadas.

Para os procedimentos didáticos adotados na disciplina, buscou-se pela exploração do método de design para fundamentação do percurso metodológico que apoiaria as ações de design pelo alunos. 
Para isso, utilizou-se como inspiração a modelagem do fluxo proposto pelo Design Council ${ }^{2}$, em sua representação gráfica do método double diamond, conforme figura abaixo:

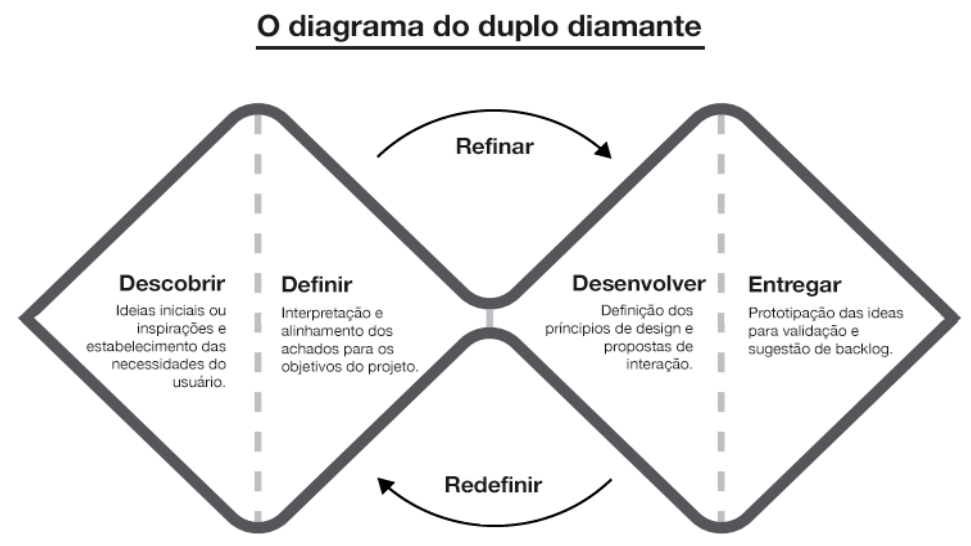

Figura 1: representação do método double diamond Fonte: Design Council².

Nessa proposta, o fluxo orientou a ação de design a partir de dois fluxos principais: corrente divergente responsável pela etapa de descoberta e exploração do problema, precedida pela etapa convergente que se orienta ao refino e seleção da oportunidade de ação. Após essa identificação recomeça o fluxo divergente com o intuito de levantar alternativas para a proposição em design que culmina na prototipação da solução diagnosticada. Como eixo central desse fluxo, considerou-se a identificação da demanda de design, selecionada a partir da identificação das etapas descobrir e definir. Em seguida, a demanda se tornou o elemento central para o qual a ação de design buscou em seu processo a construção de uma resposta e solução.

Nessa perspectiva, a demanda nasce da exploração do problema e a busca por alternativas levam a identificação da demanda e por conseguinte a solução. Durante o semestre, o conceito de metaprojeto, desenvolvido por Moraes (2011), foi trabalhado na disciplina como pensamento de um modelo adequado às abordagens do mundo complexo. De forma que, as soluções em design requerem um olhar holístico que compreende a natureza complexa e sistêmica humana, social, cultural e etc. De modo, que a exploração das etapas do método de design corrobora para uma ação comprometida com a realidade contextual.

Bauman (2011) discute as definições dessa sociedade contemporânea que está inserida em um complexo contexto de constante transformação interagindo em um sistema composto por inúmeros elementos, camadas e estruturas que se dialogam e inter-relacionam, condicionando e redefinindo continuamente o seu funcionamento. Nessa conjuntura, o trabalho do design tem sido possibilitar e ajustar conexões entre elementos que antes estavam desconexos (CARDOSO, 2012). Para que isso seja possível, o designer passa a identificar a natureza dos problemas nessa sociedade e atua na concepção de possíveis respostas.

Nesse sentido, o designer enxerga como um problema tudo aquilo que prejudica ou impede a experiência humana (emocional, cognitiva, estética) e o bem-estar na vida das pessoas, considerando todos os aspectos da vida, como trabalho, lazer, relacionamentos, cultura, dentre outros. Isso faz com que sua principal tarefa seja identificar problemas e gerar soluções (VIANNA et al, 2012).

A maneira como a sociedade enxerga o design também modificou com o tempo. Os gestores das empresas e instituições perceberam a forma como o designer compreende as questões e age sobre elas, passando a integrar esses profissionais na gestão das empresas. De forma que, a visão holística

\footnotetext{
${ }^{2}$ Método "Double Diamond" conhecido por "Diamante duplo", elaborado pelo Design Council, uma instituição independente e de consultores em design. Atuam na promoção do papel e valor do design mediante melhoria de processos, produtos e desempenhos. Disponível em: <https://www.designcouncil.org.uk/news-opinion/whatframework-innovation-design-councils-evolved-double-diamond $>$. Acesso em 10 de agosto de 2020.
} 
para a inovação que o designer possui e seu método de trabalho permite que as empresas compreendam melhor seus usuários, suas expectativas e contextos, promovendo soluções co-criadas entre as equipes e usuários, bem como a prototipação para validação e entendimento das necessidades dos envolvidos, ao longo de um processo de geração de soluções inovadoras e eficazes (VIANNA et al, 2012).

Nessa perspectiva de ampliar os horizontes dos campos de atuação do design na sociedade apresentamos os quatros estágios desenvolvidos por Thenint (2009), conjuntamente ao centro de design dinamarquês, sobre as aplicações do design em uma empresa. O primeiro estágio são empresas que não usam o design e não entendem seu valor e sua aplicabilidade no mercado. A segundo fase são empresas que usam o design por estilo ou aparência, somente na finalização do processo. $\mathrm{O}$ terceiro grau são empresas que integram o design no processo de desenvolvimento do produto e serviço e o quarto e último estágio são empresas que consideram o design um elemento estratégico em todo o processo de solução, seja na etapa de criação, elaboração, distribuição e análise pós-implementação do produto e/ou serviço.

Conjuntamente, Jones (2013) define quatro estágios de atuação do designer: o primeiro é o design tradicional feito a partir de projetos de artefatos, espaços e comunicação. O segundo considera o design de serviço no qual há criação de valor, com inovação no produto, canais que proporcionam a experiência do usuário e o designer como integrante. O terceiro estágio compreende complexidades de transformação organizacional delimitadas por negócios ou estratégias, orientado para as mudanças. A última conjuntura é o design para transformação social, no qual, lida com situações sociais complexas, sistemas sociais, elaboração de políticas e desenho de comunidades. Essas diferenças de abordagem do design que passa pela solução de projeto como também uma transformação social reconsiderou o papel do design na sociedade contemporânea.

\section{Relato de experiência}

Sobre a abordagem de ensino e aprendizagem adotada nessa prática docente considerou-se inicialmente o repasse de conteúdos teórico, expositivo e dialogado, conforme referenciado acima, que permitiram a construção de fundamentos teóricos e reflexões acerca do design, método e atuação. A partir disso, o discente pôde construir referenciais sobre a gestão do design, método de design e a prática de exercícios orientados a busca dos conceitos aplicados. Compreende-se que esta etapa de fundamentação foi imprescindível para o amadurecimento do olhar e formação do aluno ao longo do processo. Após esta etapa de fundamentação o aluno pôde, por meio de uma vivência projetual, aplicar os conceitos adquiridos e explorar caminhos de proposição para além do campo projetual em design de interiores, que compreendessem o pensamento estratégico em design.

Todo o conteúdo apresentado possibilitou a ampliação de repertório sobre as diferentes possibilidades de atuação do designer na sociedade e se tornou subsídio para o desenvolvimento do trabalho final elaborado pelos alunos e que será apresentado a seguir, em formato de relato de experiência.

Vale ressaltar que, em função das regras de isolamento social impostas pelas autoridades competentes, orientadas a prevenção e repressão da pandemia ocasionada pela Covid-19, no primeiro semestre de 2020, as disciplinas do Curso tecnólogo de Design de Interiores foram ofertadas de modo remoto. Sendo que, todos os procedimentos de aulas, orientações de trabalhos e realização de atividades foram realizados por plataformas virtuais da própria instituição e pela plataforma Zoom. A disciplina em questão foi ofertada em três campus, sendo eles: Belo Horizonte, Contagem e Betim. Mesmo havendo proximidade geográfica entre as cidades e campus, os trabalhos demonstraram especificidades de cada contexto em questão.

A proposta do trabalho final consistiu na identificação de situações problemas, presentes no cotidiano das cidades, a partir da perspectiva dos alunos. A atividade iniciou com a identificação de demandas, mediante a exploração de problemas na cidade. Na sequência, foi selecionado um problema que poderia ser respondido pelo design. A partir disso, iniciou-se o processo de concepção de um um serviço de design para a questão identificada. Para o desenvolvimento deste exercício prático os 
alunos tiveram sete semanas para sua execução. Para exemplificar os resultados obtidos neste exercício prático foi selecionada uma amostra de cada campus.

No campus de Betim, a turma foi dividida em quatro grupos que apresentaram soluções distintas para diferentes cidades. Um grupo apresentou uma solução de dois modelos de lixeira para a coleta seletiva na cidade de Betim - MG. O segundo grupo apresentou soluções para autoescolas nesse novo contexto imposto pela Covid-19 na sociedade. O terceiro grupo tratou da falta de identidade, de cuidado e preservação em relação a cidade de Betim, de forma a incentivar os cidadãos betinenses a cuidar da sua cidade como se fosse sua casa. Por último, um grupo ${ }^{3}$ propôs criar vários serviços para a cidade de Rio Manso - MG, utilizando do design de experiência para valorizar a cultura da cidade. Esse último trabalho foi o escolhido para ser retratado neste artigo.

Os alunos elegeram a cidade de Rio Manso como fonte de pesquisa. Rio Manso tornou-se município em 30 de dezembro de 1962. Seu nome é devido ao rio com águas mansas e tranquilas que corta a cidade. Atualmente Rio Manso possui 6000 habitantes que sobrevivem com o cultivo de hortifrutigranjeiros. O município pertence à região metropolitana de Belo Horizonte e está localizado na Região Geográfica Metalúrgica de Minas Gerais. A cidade fica a 62 quilômetros de distância da capital mineira (RIO MANSO, 2020).

O grupo identificou como problemas do município a subutilização das belezas naturais da região e da mão de obra local. Na sua pesquisa eles realizaram um questionário online com os moradores para descobrir os principais problemas e demandas existentes na cidade.

O resultado do questionário apresentou que $28,6 \%$ dos entrevistados sentem falta da geração de emprego na cidade, juntamente com $28,6 \%$ na falta de estrutura para o lazer e o turismo no município. Em terceiro lugar, com $20 \%$, foi identificada a falta de infraestrutura como pavimentação das ruas e acessos. Em quarto lugar, com 17,1\%, foi elencado a saúde, e uma constatação do grupo foi que no início do questionário, a pandemia da Covid-19 não estava grave no estado de Minas Gerais e esse tópico não havia aparecido como problema. Com o passar dos dias, muitos moradores questionaram a falta de estrutura dos postos de saúde na cidade devido ao agravamento da pandemia. Por último, com 5,4\% apareceram temáticas relacionadas à falta de identidade na cidade, estrutura das escolas, entre outros elementos.

Devido ao resultado do questionário, os alunos criaram a solução: Bem Mineiro, que consiste em um conjunto de proposta que beneficiam a cidade para solucionar os principais problemas de Rio Manso que é falta de emprego e de espaços para lazer e turismo. As ações seriam possíveis por meio da união de trabalho entre as esferas público e privado. A proposta apresenta quatro soluções distintas, mas todas valorizando a história e o patrimônio natural da cidade de Rio Manso. Elas são: a criação de um restaurante com culinária tipicamente mineira, onde os produtos são, em sua maioria, oriundos da agricultura familiar e de pequenos produtores, dando valor ao que é produzido na região. A exemplo: Broa das Almas feita com coalhada fermentada no milho, o frango com quiabo e frango com ora-pronóbis, fomentando a economia local. A segunda solução é uma venda de produtos artesanais localizada em anexo ao restaurante, denominada Venda do Chico, em homenagem a uma antiga mercearia que existia no distrito de Cachoeira dos Antunes. Em caráter explicativo, Cachoeira dos Antunes era distrito de Rio Manso e foi inundada para a criação da barragem de Rio Manso pela Copasa no ano de 1989. Com a inundação todo o distrito ficou submerso e deixaram de existir elementos ícones para os moradores como o moinho e a Igreja Nossa Senhora do Perpétuo Socorro, a exemplo na Figura 2. Como forma de resgatar a cultura local, os artesãos iriam produzir o moinho e a igreja em miniatura para serem vendidos na Venda do Chico, junto com os móveis rústicos, queijo, doces, tudo produzido pelos moradores em parceria com as oficinas locais.

\footnotetext{
${ }^{3}$ Grupo composto por Alice Carolina Palhares Chaves; Ana Luíza Loredo Rocha; Daniel José Ferreira; Vanessa Nepomuceno Macedo e Verônica Ribeiro de Andrade.
} 


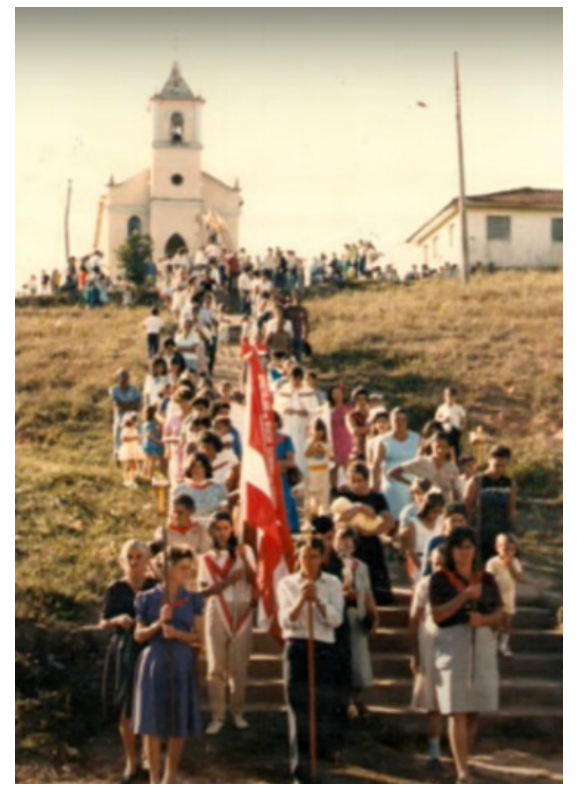

Figura 2: Festividade na frente da Igreja Nossa Senhora do Perpétuo Socorro.

Fonte: apresentado pelo grupo de alunos, 2020.

A terceira solução foi a valorização dos elementos naturais da região com a criação de roteiros turísticos, que hoje apresentam mais de dez lugares para visitação a exemplo da Cachoeira do Morro da Onça, Cachoeira do Zé Velho, Cachoeiras das Sete Quedas, Represa da Copasa, entre outros. Somados a esses roteiros serão incluídas as festas locais como incentivo às atrações turísticas como a Festa de Santa Luzia, Festa da Cerâmica, Festival de Folia de Reis, Festa da Couve-flor entre outras.

Como quarta e última solução os alunos propuseram a criação de hospedagens turísticas, subdividida em três segmentos. A primeira é denominada São Thomé, uma área de camping para turistas simples, com instalações em meio a natureza com pontos para acendimento de fogueiras e banheiros. A segunda intitulada Tiradentes possuirá pousadas com construções rústicas do estilo barroco. E por último, Monte Verde com hospedagens luxuosas no estilo europeu com a criação de quiosques individuais.

A realização desse conjunto de soluções seria efetuada por etapas, primeiro a criação da loja de artesanato e restaurante junto a criação e divulgação dos roteiros turísticos. Posteriormente, depois da verificação efetivas das ações anteriores seria realizada a constituição das hospedagens.

No campus de Belo Horizonte os alunos apresentaram cinco propostas de design para mitigar problemas identificados na cidade, foram elas: 1) Solução de design para promoção de alimentação de qualidade para moradores de baixa renda. 2) Banho de Amor - uma ação que buscou identificar como o design pode contribuir para replicar um projeto de impacto social em outras cidades e proporcionar a outros moradores "em situação de rua" uma oportunidade de reinserção social. 3) Fortalecimento do Turismo da cidade de Oliveira, mediante o mapeamento de um circuito turístico. 4) Contribuições do design para apropriação de parques públicos: estudo de caso no Parque Municipal Américo Renné Gianneti. 5) Proposição de um circuito cultural para o edifício Acaiaca: uma ação orientada ao acesso participativo aos edifícios históricos da cidade de Belo Horizonte.

Dentre as ações, elegeu-se para este relato a "1) Solução de design para promoção de alimentação de qualidade para moradores de baixa renda". Como problema norteador compreendeuse: Como levar alimentos frescos e de qualidade para a população de baixa renda de Belo Horizonte? A partir de um processo de contextualização do problema o grupo ${ }^{4}$ explorou as causas responsáveis e a

\footnotetext{
${ }^{4}$ Grupo composto pelas alunas do curso de design de interiores de um Centro Universitário, são elas: Gabriela Sousa, Luana Hossi, Marcella Santos e Rafaela Bicalho.
} 
partir do método de design percorreu etapas de desenvolvimento que culminaram na apresentação de uma solução.

A contextualização do problema compreendeu o levantamento sobre o cenário da alimentação, uso de substâncias agrotóxicas no cultivo e dados sobre a saúde. Foram levantadas iniciativas existentes que tangenciam o problema e realizadas análises. A partir disso, o grupo elegeu como demanda a "necessidade de pensar soluções a baixo custo para garantir acesso das pessoas de baixa renda a alimentação de qualidade e práticas agroecológicas". Geraram alternativas e registros visuais a partir da ferramenta moodboard para visualização de obras análogas.

Propuseram como solução um projeto intitulado "Favela Orgânica" que tem por objetivo levar aos moradores da comunidade "Aglomerado da Serra" alimentos frescos e livres de agrotóxicos. Com caráter interdisciplinar, o projeto conta com o apoio de diversos profissionais e da comunidade para implementar todas as etapas. A escolha dessa comunidade se deve ao fato de ser a maior favela de Minas Gerais, localizada em Belo Horizonte, mais precisamente na Zona Sul da capital, sendo uma das maiores favelas do Brasil. Foi realizado um levantamento do território que compreendeu a formação das vilas; veículos de comunicação local; aparelhos sociais.

A Prototipação consistiu no desenvolvimento de um projeto que auxilie os moradores a produzir e distribuir alimentos orgânicos à um custo acessível. Assim, o projeto será implementado com o auxílio de uma equipe multidisciplinar e será desenvolvido no decorrer de seis etapas, que incluíram desde a propagação de informações sobre alimentação saudável até o planejamento de comercialização da produção. O fluxo da solução prototipada pode ser observado na Figura 3.

\section{PROTOTIPAÇÃO}

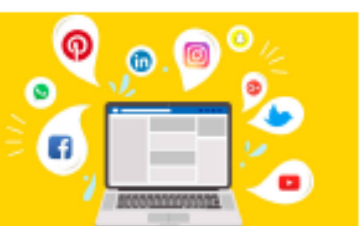

\section{$1^{\text {a ETAPA: }}$ \\ INFORMACÃ் E CONSCIENTIZACCẪO}

Desenvolvimento de uma equipe multidisciplinar como o objetivo de levar para a comunidade informaçōes sobre a importância de uma alimentaçāo saudável, os maleficios dos agrotóxicos e do desperdicio de alimentos.

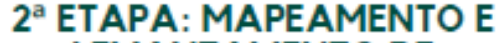 LEVANTAMENTO DE RECURSOS}

Nessa etapa, o objetivo será identificar quais os locais seriam adequados para o plantio das hortas, arrecadar fundos e encontrar parceiros para o projeto.

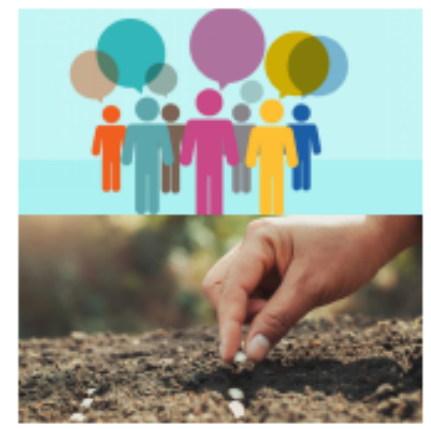

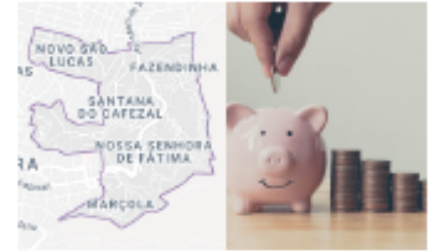

$3^{\text {a }}$ ETAPA: CRIACÃ̃O DE EQUIPES E PLANTIO DE SEMENTES

Cadastramento dos moradores interessados em participar do projeto, dividindo-os em equipes. Cada equipe ficaria responsável por um setor já definido na etapa de mapeamento. Essas equipes seriam responsáveis pela implantaçāo e manutençāo das hortas, bem como a distribuiçāo da produçōo. 


\section{$4^{\text {a ETAPA: }}$ \\ PLANTIO E MANUTENÇÃO DAS HORTAS \\ As mudas produzidas sāo distribuidas para equipes, que serāo responsáveis pela manutençāo das hortas, plantio de novas mudas e distribuiçāo do que for produzido.}

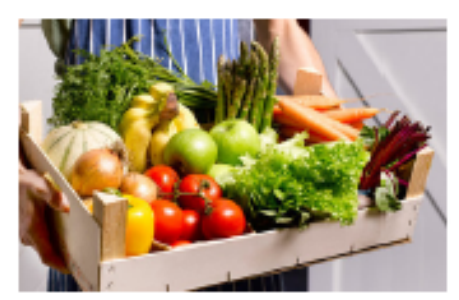

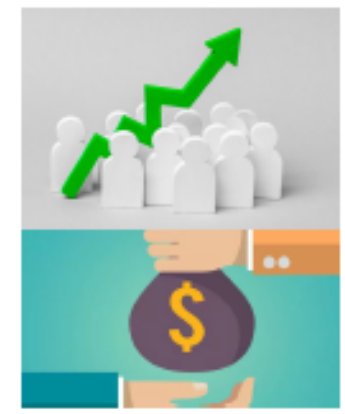

\section{5 aTAPA: \\ PLANO DE DISTRIBUICุÃO E EXPANSÃO}

Ao chegar na $4^{\circ}$ etapa e constatar o sucesso da implantaçāo do projeto, é hora de expandir para as demais comunidades do aglomerado, adotando as mesmas etapas e adequando o que for preciso. Quando a quantidade produzida ultrapassar suas necessidades, o excesso passará a ser vendido para a comunidade a preços baixos.

\begin{abstract}
$6^{\circ}$ ETAPA:
CRIAČÃO DE FEIRAS ORGÂNICAS

Etapa iniciada depois da expansāo das hortas e superproduçāo, para gerar renda para os moradores da comunidade, e o alimento de qualidade chegar por um preço justo para as outras pessoas da comunidade
\end{abstract}

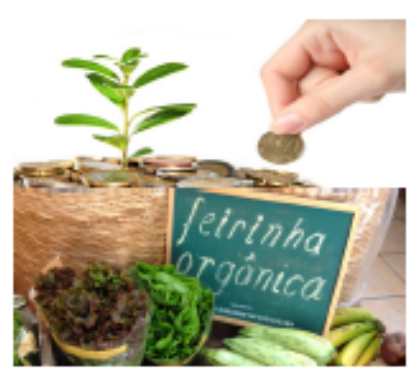

Figura 3: fluxo de etapas para prototipação da solução Fonte: elaborado pelo grupo de alunos, 2020.

No campus de Contagem os temas apresentados pelos grupos foram: 1) Comboio Cultural educação para todos em tempos de pandemia. 2) Criação de um co-maker (espaço de produção coletiva) para elaboração, desenvolvimento e execução de projetos de marcenaria, dentre outras especificidades do design de interiores. 3) Contribuições do design para o terceiro setor: estudo de caso na instituição Caminhos para Jesus.

Dentre as ações, elegeu-se para este relato a "1) Comboio Cultural - educação para todos em tempos de pandemia" pela sua relevância e aplicabilidade no cenário atual. Assim, o projeto Comboio Cultural realizado por um grupo de alunos ${ }^{5}$, se orientou a exploração do problema que compreendeu a cidade de Contagem/MG e considerou um olhar da gestão do design para a educação de crianças e jovens de baixa renda no atual cenário da pandemia mundial Covid-19. Com base no artigo 205 da Constituição Federal de 1988 que garante a educação um direito de todos e dever do Estado e da família, que devem promover e incentivar a colaboração da sociedade, visando ao pleno desenvolvimento da pessoa, seu preparo para o exercício da cidadania e sua qualificação para o trabalho.

A partir de pesquisas e levantamentos para caracterização do território, identificou-se que a inclusão digital ainda não é uma realidade efetiva em grande parte do município de Contagem e, portanto, um grande número de crianças e jovens, entre 5 a 18 anos, não possuem equipamentos e mídias digitais que lhes garantam o acesso a meios de aulas virtuais. Nesse sentido, tornou-se necessária uma ação orientada a criação de uma estratégia que garanta o acesso à educação, que vise a humanização e a garantia de condições favoráveis e seguras.

\footnotetext{
${ }^{5}$ O grupo que realizou a ação foi composto pelos alunos: Adriana Fantini, André Luiz, Caroline Evangelista, Kamila Cristina e Rosiméria Garcia.
} 
Conforme dados levantados do Atlas Brasil ${ }^{6}$, identificou-se a proporção de crianças e jovens frequentando ou tendo completado os ciclos educacionais: de 05 a 06 anos $=92,65 \%$; de 11 a 13 anos $=87,94 \%$; de 15 a 17 anos $=66,08 \%$ e de 18 a 20 anos $=48,08 \%$. A mesma fonte afirma que a população de 6 a 17 anos, cursa o ensino básico regular, com até dois anos de defasagem idade-série pelos indicadores de 2010 correspondendo a 86,10\%; em 2000 a 83,53\% e em 1991 a 71,59\%.

Para identificação do campo de estudo foi considerada uma região de atuação dentro de um raio de $25 \mathrm{~km}$ no bairro Nova Contagem. A escolha do local se deve ao fato de abrigar um número relevante de escolas públicas, como pode ser observado na Figura 4:

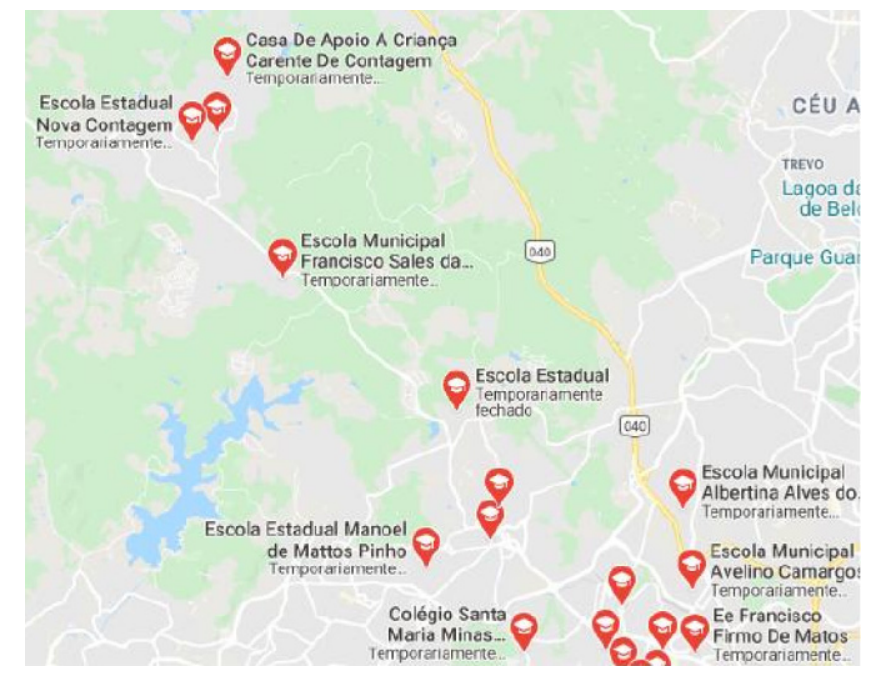

Figura 4: Demarcação das escolas públicas localizadas no bairro Nova Contagem Fonte: Google Maps, 2020.

Como parte do diagnóstico de identificação da oportunidade de ação em design o grupo elegeu como demanda: a necessidade de levar a educação continuada em formato de livros, materiais impressos e materiais escolares diversos para garantir e preservar o direito à educação. Assim, foi elaborado um sistema de educação à distância, por meio de um veículo itinerante para dar assistência aos alunos carentes sem acesso ao ensino por meios digitais.

A solução de design consistiu na adequação de veículos "Vans" adaptadas para ajudar a reinventar, e experimentar um novo formato, que gere como parte dos resultados a manutenção dos empregos de professores, educadores, incluindo os motoristas de Vans habilitados.

Como parte do processo de geração de alternativas identificou-se como possibilidade o uso de veículos de transporte escolar, com soluções de fácil adaptação, sem elevar os custos. O uso de ímãs de propaganda nos veículos, permite a criação da identidade visual do projeto, mediante manta magnética $0,7 \mathrm{~mm}$, adaptável a qualquer tamanho desejado (Figura 5).

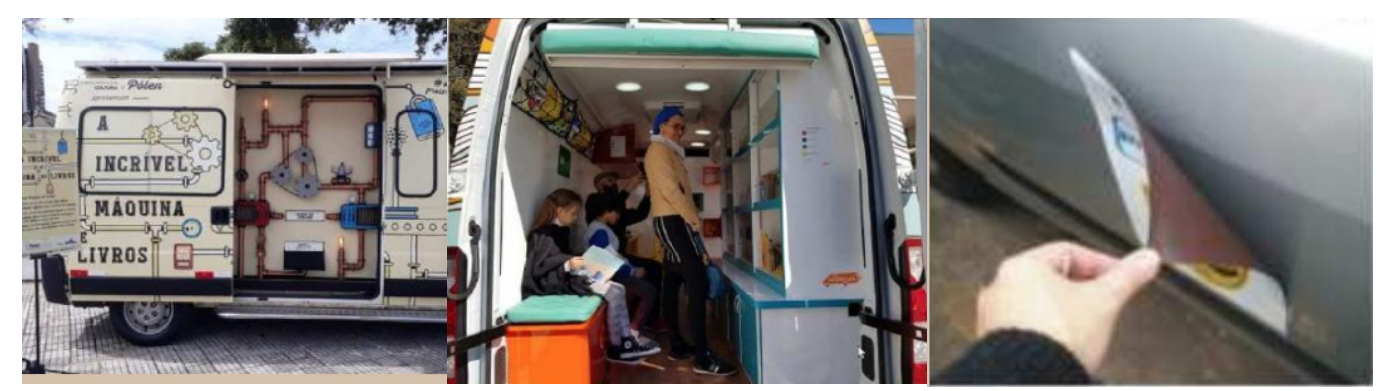

Figura 5: Painel de imagens com referências visuais para adequação do veículo Van Fonte: Google Imagens; https://www.traconet.com.br/imas-propaganda-veiculos/

\footnotetext{
${ }^{6}$ Dados apresentados pelo Atlas Brasil. Disponível em: <http://www.atlasbrasil.org.br/2013/pt/perfil_m/5164>. Acesso no dia 19 de Junho de 2020.
} 
No que tange a aplicabilidade da solução proposta serão distribuídos quinzenalmente, materiais didáticos (existentes), caderno de exercícios, este com data para recolhimento e correção, livros de leitura complementar (em caráter de empréstimo), com percursos previamente mapeados até a residência do aluno ou pontos próximos. Abaixo segue Figura 6 com a demarcação dos indicadores previstos para monitorar a viabilidade e efetividade da solução:

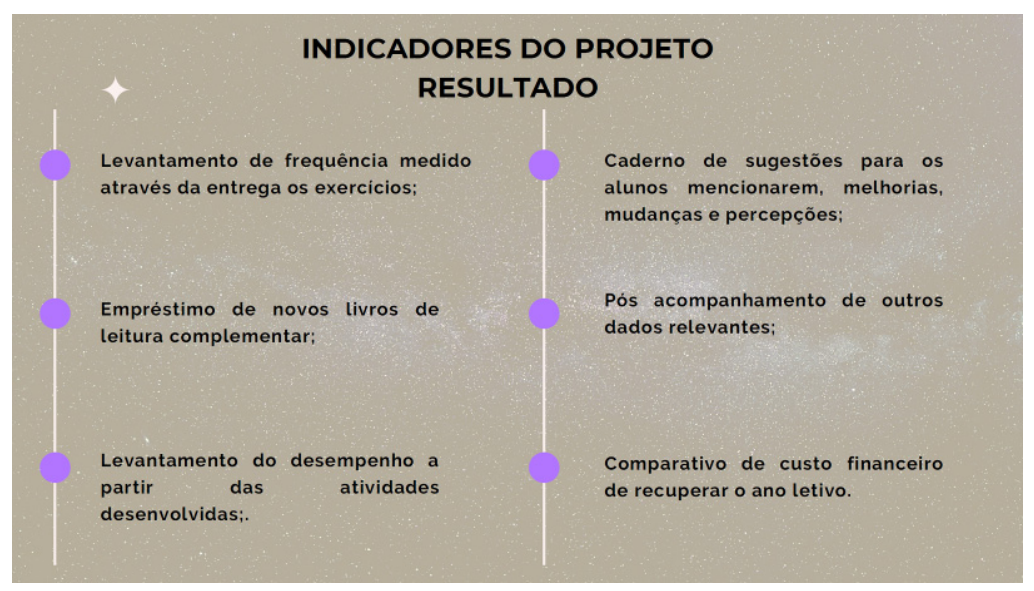

Figura 6: Indicadores de viabilidade e efetividade da solução

Fonte: grupo de alunos responsáveis pela elaboração da solução

Os trabalhos apresentados demonstram a relação que os alunos desenvolveram com os fundamentos em design e os problemas identificados nas cidades propondo soluções reais e factíveis para tais demandas.

\section{Considerações Finais}

Os trabalhos apresentados exemplificam a relação que os alunos desenvolveram com as temáticas trabalhadas em sala de aula e demonstram a obtenção do entendimento do papel do design no contexto urbano, social, cultural, dentre outros.

Todos os trabalhos foram apresentados para bancas compostas por profissionais em design e arquitetura. Na solução para a cidade de Rio Manso a banca reconheceu as inúmeras possibilidades de solução aos problemas apresentados e a relevância das propostas, mas questionou sobre a falta de diagramação sistêmica das fases e maneiras como os serviços iriam ser executados, como também, a ausência da identificação dos stakeholders e suas contribuições nas etapas do serviço. Por ser uma ação macro, carecia estabelecer as etapas das micro ações que facilitaria e implementação das propostas estabelecidas.

$\mathrm{Na}$ experiência do campus Belo Horizonte os componentes da banca observaram a necessidade de maior articulação do design com o local escolhido, apresentando os possíveis parceiros da proposta. Eles, também, questionaram a necessidade do planejamento da identidade visual para os materiais de divulgação e comunicação do projeto, de forma que essa deveria apresentar maior relação com o projeto proposto.

No campus de Contagem, a única recomendação apresentada pela banca no projeto Comboio Cultural - educação para todos em tempos de pandemia, foi aumentar a frequência do monitoramento, de forma que esse professor consiga acolher melhor os alunos.

Para o desenvolvimento das soluções aqui apresentadas deve-se ressaltar alguns elementos dificultadores como o pouco tempo para a execução do trabalho prático e o contexto de saúde atual imposto pela pandemia da Covid-19. Embora as dificuldades apresentadas, os trabalhos apresentaram altos níveis de compreensão da atuação e do papel do design na sociedade. E a apresentação da solução para as bancas possibilitou identificar os déficits dos alunos, como também, pontuar futuras melhorias para a continuação dos seus estudos.

Dessa forma, os alunos entenderam a aplicabilidade do design para atuar junto às questões reais das cidades, seja pela dimensão estratégica do design; pela dimensão projetual orientada ao planejamento de ambientes; ou mesmo, pela co-participação do usuário no processo de elaboração da 
solução proposta. Assim, a ação possibilitou a ampliação dos horizontes dos alunos e docentes, sobre a atuação do designer como um agente fomentador, articulador social e que desenvolve ações a partir de abordagens que integram os diferentes atores da comunidade.

Compreende-se assim, que apesar do curso tecnólogo possuir menor tempo de formação, há possibilidade de fomentar o pensamento estratégico em design, mediante abordagens pedagógicas que impulsionam o protagonismo discente. Sobretudo, a exposição teórica e aplicada do método de design, permite a compreensão de uma atuação comprometida com o bem-estar social e que relaciona a complexidade. Dessa maneira, os discentes passam a identificar seu papel na sociedade e impulsionados pelas experiências de aprendizagem, poderão dar prosseguimento na construção contínua de sua formação, mediante o desenvolvimento de novas competências, habilidades e especialidades a serem adquiridas por novas vivências na pós-graduação.

What graduate course can expect from undergraduate student in Interior Design: experience report in the discipline Interdisciplinary Project

\section{abstract:}

This article comprises the report of theoretical-practical experience of teaching worked in the discipline Interdisciplinary Project in the technologist course in interior design, accomplished at three campuses in the metropolitan region of Belo Horizonte - MG. The research showed real situations, present in the complex scenario that involves acting in design and promotes continuing education for technologist students in graduate school. For this purpose, a theoretical path will be presented that founded the theoretical-reflective constructions, such as: higher education in interior design; the didactic processes adopted in the discipline; the protagonism of the student; design method and tools that explore the procreate of solutions that touch strategic dimensions in design. As part of the methodological design, the article is characterized by qualitative research with an exploratory study to support theories and experience reporting that made it possible to highlight teaching practices and results obtained with project experimentation.

Key-words:

Technological Training; Interior Design; Strategic Design; Experience report

\section{Referências}

BAUMAN, Zygmaunt. Modernidade Líquida Rio de Janeiro: Jorge Zahar, 2001.

CARDOSO, Rafael. Design para o mundo complexo. São Paulo: Cosac Naify, 2012.

CELESTINO et al, 2020. Metodologias ativas de ensino - aprendizagem da formação de

enfermeiros. Revista Artigos.com, volume 17, 2020.

DESIGN COUNCIL. Disponível em: <https://www.designcouncil.org.uk/who-we-are/our-mission>. Acesso em 10 de Agosto de 2020.

FERNANDES, Domingos. Ensino e avaliação no ensino superior: reflexões a partir da pesquisa realizada no âmbito do projeto Avena. Cad. Cedes, Campinas, v. 36, n. 99, p. 223238, maio-ago., 2016. 
JONES, Peter H. Systemic Design Principles for Complex Social Systems. Social Systems and Design, Gary Metcalf editor. Volume 12013

MINISTÉRIO DA EDUCAÇÃO. Diploma dos tecnólogos vale para concursos e pós graduação. Disponível em: http://portal.mec.gov.br/busca-geral/209-noticias/564834057/15698-diploma-dostecnologos-vale-para-concurso-e-pos-graduacao acessado em 14 de agosto de 2020.

MINISTÉRIO DA EDUCAÇÃO. PORTAL DO MEC - E-MEC -CONSULTA INTERATIVA, 2020.

Disponível em: http://emec.mec.gov.br/acessado em 20 de agosto de 2020.

MINISTÉRIO DA EDUCAÇÃO. PORTAL DO MEC - E-MEC -CONSULTA TEXTUAL, 2020. Disponível em: http://emec.mec.gov.br/acessado em 20 de agosto de 2020.

MORAES, Dijon de. Metaprojeto como modelo projetual. In: Strategic Design Research Journal, p. 62-68 maio-agosto, 2010.

RIO MANSO. História de Rio Manso. Disponível em: https://www.riomanso.mg.gov.br/detalhe-damateria/info/historia-de-rio-manso/6501 acessado em 21 de agosto de 2020.

SCHNAIDER, Sílvia Helena de C. ; FREITAS, Sydney Fernandes de. Os cursos superiores de design no Brasil. Diálogo com a Economia Criativa, Rio de Janeiro, v. 1, n. 3, p. 58-75, set./dez. 2016.

SCHNAIDER, Sílvia Helena de C. ; FREITAS, Sydney Fernandes de.

A distribuição dos cursos superiores no Brasil. $2^{\circ}$ SIMPÓSIO DE PÓS-GRADUAÇÃO EM DESIGN DA ESDI. Rio de Janeiro, 2016.

THENINT, J Rosttedt in. A escada do Design. In Commission of the European Communities. Design as a driver of user-centred innovation. Brussels, 2009.

VIANNA, Maurício; et al. Design thinking: inovação em negócios. Rio de Janeiro: MJV Press, 2012. 